\title{
Pregnancy and birth in HIV seropositive women - present stage results
}

\author{
Mihai Mitran ${ }^{*}$, Carmen Georgescu', Mariana Mărdărescu², Bogdan Marinescu', Andreea Velişcu', loana Roşca', \\ Marcela Șerban ${ }^{3}$
}

From The 9th Edition of the Scientific Days of the National Institute for Infectious Diseases Prof Dr Matei Bals Bucharest, Romania. 23-25 October 2013

\section{Background}

Since 1992, the Clinical Hospital of Obstetrics and Gynecology "Prof. Dr. Panait Sârbu", Bucharest has been the medical unit to consult, record and monitor pregnancies, births and miscarriages associated with transmittable diseases - including HIV positive patients from Bucharest and the surrounding counties, as the hospital had the necessary professional expertise and intrahospital networks. In time, within the "Prof. Dr. Panait Sârbu" Clinic, we have systematized and implemented an obstetric protocol for the prevention of HIV vertical transmission.

\section{Methods}

The aim of this protocol has been to reduce the HIV vertical transmission rate from $30-35 \%$, the value in 2000 , to $2-3 \%$, the rate recorded in the European developed countries.

Starting from the primordial objective to decrease mother-to-child vertical transmission rate, we established the cesarean section as the method of delivery for all HIV positive women, at 37-38 weeks, on intact membranes, outside labor. The result was a significant decrease in the number of HIV positive babies.

\section{Results}

The results of the past 7 years have been most encouraging, with a 0 rate of vertical transmission through $\mathrm{C}$-section, and a $23.63 \%$ transmission for vaginal delivery.

\footnotetext{
* Correspondence: michael_digital@yahoo.com

'Clinical Hospital of Obstetrics and Gynecology "Prof. Dr. Panait Sârbu", Bucharest, Romania

Full list of author information is available at the end of the article
}

\section{Conclusion}

Attentive monitoring of pregnancy by the obstetrician in cooperation with the infectious diseases specialist, delivery by $\mathrm{C}$-section, complex antiretroviral therapy for both mother and child and ablactation have been the main means through which a spectacular decrease in HIV vertical transmission has been achieved.

\section{Authors' details}

'Clinical Hospital of Obstetrics and Gynecology "Prof. Dr. Panait Sârbu", Bucharest, Romania. ${ }^{2}$ National Institute for Infectious Diseases "Prof. Dr. Matei Balş", Bucharest, Romania. ${ }^{3}$ The Institute for Mother and Child Protection "Alfred Rusescu", Bucharest, Romania.

Published: 16 December 2013

\section{doi:10.1186/1471-2334-13-S1-034}

Cite this article as: Mitran et al:: Pregnancy and birth in HIV seropositive women - present stage results. BMC Infectious Diseases 2013 13(Suppl 1):O34. and take full advantage of:

- Convenient online submission

- Thorough peer review

- No space constraints or color figure charges

- Immediate publication on acceptance

- Inclusion in PubMed, CAS, Scopus and Google Scholar

- Research which is freely available for redistribution 